\title{
RELACIONES INTERGENÉRICAS EN LA OBRA DE FERNÁNDEZ DE LIZARDI (SOBRE PERIODISMO, NARRATIVA Y OTRAS IMPLICACIONES)
}

\author{
Ángel Estévez Molinero \\ Universidad de Córdoba
}

\begin{abstract}
RESUMEN: El presente artículo analiza las relaciones que, en el marco de la obra de Fernández de Lizardi, se establecen entre el periodismo, siempre como instrumento básico de referencia, y los diversos géneros mayores y menores, sobre todo la narrativa, empleados pragmáticamente por su utilidad literaria y social. Se pretende, con ello, destacar el carácter orgánico de su producción y ofrecer al mismo tiempo una visión unitaria del conjunto, evitando incidir en el estudio particular de un determinado género.
\end{abstract}

PALABRAS CLAVE: Lizardi, ilustración, periodismo, literatura, géneros, pragmática.

\section{INTERGENERIC RELATIONSHIPS IN FERNÁNDEZ DE LIZARDI'S WORK (ABOUT JOURNALISM, NARRATIVE AND OTHER IMPLICATIONS)}

\begin{abstract}
This paper analyses the relationships that, in Fernández de Lizardi's framework, are established between journalism, searched as a basic tool of reference, and several major and minor literary genres, mainly narrative, which are used due to their literary and social utility from a pragmatic viewpoint. It aims to highlight the organic character in their production and to offer, at the same time, an overview, avoiding the insistence on the particular study of a certain genre.
\end{abstract}

KEYWORDS: Lizardi, enlightenment, journalism, literature, genres, pragmatics.

Afirma Alfonso Reyes, con su habitual perspicacia, que José Joaquín Fernández de Lizardi, El Pensador Mexicano, "como quiera que se le considere, es un centro" (Reyes 1975: 143). Las razones de tal consideración son múltiples; lo es, 
porque su vida y su obra se inscriben centralmente en el periodo que transcurre desde la crisis del sistema colonial y la fase insurgente hasta la Independencia y los primeros años del estado moderno; porque, literariamente hablando, en él confluyen una palabra rígida y unas formas estereotipadas, que él inflexiona en buena medida, adecuándolas práctica y pragmáticamente a sus objetivos ilustrados y que, además, las proyecta fundacionalmente sobre muchas de las corrientes esenciales de la literatura mexicana que llegan a nuestros días; en fin, porque no es un excéntrico (en el sentido de operar por los extremos), sino un criollo intelectual que se columpia en las contradicciones, sin duda porque aprecia racionalmente la doble faz que presentan las cosas y los hechos (Ruiz Barrionuevo 1991:78), lo que traduce inevitablemente la ambigüedad de sus actitudes. Esto es algo que no debe sorprendernos si tenemos en cuenta las urgencias históricas del tiempo en que le tocó nacer, la peripecia personal vivida en tales circunstancias y una obra que, por implicada en la vida y en la historia, se concibe como un modus vivendi et operandi. Ahora bien, para evitar la complacencia en perfiles históricos y biográficos distractores, conviene precisar el alcance de tales aspectos. Ya Mariano Azuela (1947) y Agustín Yáñez (1955), los primeros que se preocuparon por entender la producción lizardiana, la naturaleza de los mecanismos formales desplegados y las razones de su funcionamiento, destacaron los estrechos vínculos existentes entre el hombre, la obra y las circunstancias, dejando claro que la proyección histórica, literaria y humana del Pensador debe deducirse de la obra con la ayuda, eso sí, de los otros dos factores. Sólo de esta forma, en efecto, podremos entender con la amplitud y la hondura necesarias, en el fragor de las contradicciones, la ambiguiedad que acompaña su proceso de búsqueda de la identidad y la expresión propias, paradigmática y sustantivamente definidas por la mexicanidad y el lenguaje.

Recordemos, pues, de forma sucinta, la incidencia de estos dos factores, la historia y la vida, en su obra (González Obregón 1938; Spell 1931 y 1964). Un hecho de la historia marcará significativamente su vida y activará, definitivamente, la escritura. Me refiero a su actuación en 1810 en Taxco: Lizardi se las ingenia para salvar la ciudad de los insurgentes, simulando que la entrega a Morelos; cuando llegan las tropas realistas, lo apresan y destruyen sus posesiones. En 1811, conseguida la liberación, pero en una situación económica dramática, recurre a la escritura como medio de supervivencia. Ese año comienza a publicar versos satíricos en el Diario de México, aunque muy pronto decide que lleguen al pueblo, divulgándolos en folletos y hojas sueltas con títulos llamativos y populares que vende por unos cuantos centavos (Martínez 1955:15). No mucho más tarde, el verso cede ante la prosa y el interés por las condiciones sociales ante la necesidad de reformas políticas. Y de los hechos, a las actitudes; si ya el episodio de Taxco resulta tan 
poco claro en cuanto al compromiso como esclarecedor de posiciones ambivalentes, el ambiente contradictorio que vive México en pro y en contra de los insurgentes se traduce en la propia postura ambigua del Pensador respecto a la independencia mexicana ${ }^{1}$. Una cosa, no obstante, queda clara y reiterada en sus escritos: ante el México que va desprendiéndose de la Colonia, "unos deseaban abolirlo por medio de la violencia, otros conservarlo intacto, prolongando con ello sus beneficios, y sólo unos cuantos, como Fernández de Lizardi, comprenderlo y corregirlo", según $\mathrm{M}^{\mathrm{a}}$. Rosa Palazón (1970: 16). No ofrece dudas, en cualquier caso, su orgullo por ver a su patria independiente ${ }^{2}$.

Sigamos el hilo de la historia, de la vida y, sobre todo, de la obra. A los cuatro días de autorizada la libertad de imprenta en México, el 5 de octubre de 1812, sale a la calle el primero y más famoso periódico de Lizardi, El Pensador Mexicano. En el número 9, continuando las denuncias de los anteriores, pide al Virrey que revoque un edicto para que unos curas revolucionarios no sean juzgados por un Tribunal militar. La consecuencia es que a los pocos días se suspende la libertad de imprenta y Lizardi, el 7 de diciembre de 1812, pasa a la cárcel, en la que permanece hasta el 7 de julio de 1813. Consecuentemente, se cancelan sus colaboraciones en el Diario de México; en la prisión, no obstante, con el tono lógicamente atemperado, redacta los números 10,11, 12 y 13 del Pensador, que prolonga su vida hasta 1814, año en el que se restablece la Inquisición; aún ven la luz Alacena de Frioleras, con el suplemento Cajoncitos de la Alacena, entre 1814-1816, y el único número de Las sombras de Heráclito y Demócrito, en 1815. Pero las circunstancias, que de nuevo han golpeado su vida, habían de repercutir en su escritura. Dice Jacobo Chencinsky que "hay un abismo entre el Pensador que se atreve y el Pensador que concede" (1968: 15); en efecto, de aquel aguerrido Pensador

1. Lizardi, en efecto, comparte los ideales de los insurgentes, pero no los medios empleados; así, mientras F. Arias-Campoamor (1952), apoyándose en su conducta posterior y en su amistad con doña Josefa Ortiz, cree que ya estaba sentimentalmente unido a los que luchaban por la independencia, otros estudiosos muestran sus reticencias al respecto por su miedo a la violencia de los insurgentes (Harold: 1949), por su ambigua actuación en Taxco (Spell: 1964; 1971) o por su defensa de la Constitución de Cádiz (Ocampo: 1967). Sirva, a modo de conclusión, lo que considera J. Chencinsky como "una contradicción desconcertante en la posición de Fernández de Lizardi, quien, por una parte, rechaza la violencia insurgente y, por la otra, coincide, sin proponérselo, con algunas de la aspiraciones fundamentales del movimiento" (1963: 42).

2. Una muestra ilustrativa de aquella posición desconcertante es su artículo "Pensamiento II: Sobre la exaltación de la nación española y abatimiento del antiguo despotismo" (Fernández de Lizardi 1968: 62-63). Con respecto a sus ideas sobre la independencia de su patria, véanse el folleto Chamorro y Dominiquín. Diálogo jocoserio sobre la independencia de América (Fernández de Lizardi 1982b: 917-18), así como Testamento y despedida del «Pensador Mexicano» (Fernández de Lizardi 1982b: 1121-25). 
Mexicano «que no le va en la zaga a don Quijote ni en lo loco ni en lo entrometido», al escritor temeroso y claudicante de la Alacena que, sin violentar sus ideas, evade el compromiso con tonos prácticos de educador, modos irónicos y chocarreros, y chascarrillos críticos, median las actitudes que ya inicialmente lo definen. En cualquier caso, y aunque sea, como indica Hodusek (1970), un motivo secundario, lo cierto es que Lizardi, convencido de la inutilidad de luchar contra las aplastantes estructuras institucionales, acaba por desplazarse a la novela. En diciembre de 1815, el Prospecto de la vida e aventuras del Periquillo Sarniento anuncia la inminente aparición de la primera gran novela hispanoamericana ${ }^{3}$, cuyo cuarto tomo no ve la luz por obra de la censura; siguen Noches tristes y día alegre (1818), el primer tomo de La Quijotita y su prima (1818) y, como él mismo asegura, tiene en 1820 la aprobación para publicar la Vida y hechos del famoso caballero don Catrín de la Fachenda. Ese mismo año, restablecidos los derechos constitucionales y la libertad de imprenta, retoma el periodismo con El Conductor Eléctrico. Pero, una vez más, la historia sale a su encuentro: ignorando los acuerdos del Plan de Iguala, publica un panfleto, Chamorro y Dominiquín. Diálogo jocoserio sobre la independencia de América, en el que defiende ésta, pero aprobada por las Cortes, lo que le lleva de nuevo a la cárcel, que aún visitará en dos ocasiones a lo largo de 1823: una, por el contenido del panfleto Si dura más el Congreso, nos quedamos sin camisa, y otra, acusado de calumnia por la dueña de la casa en que vivía. Con todo, será mucho más dura la excomunión que sufre, entre el mes de febrero de 1822 y el de diciembre de 1823, por su "Defensa de los fracmasones" con dramáticas consecuencias para su familia, para él mismo y sus escritos; sin embargo, no se arredra: «Si hay púlpitos en que me ofendan, no faltan prensas con que defenderme». Aparecen en este tiempo El Amigo de la Paz y de la Patria (1922, 1 núm.), El Payaso de los periódicos (1823, 1 núm.) y El Hermano del Perico que cantaba la Victoria (1823, 6 núms.). Normalizada de alguna manera su situación, se regulariza asimismo su actividad periodística: en 1824-25 aparecen las Conversaciones del Payo y el Sacristán (50 núms.) y, en 1826-27, El Correo Semanario de México (24 núms.).

Ahora bien, atraída la crítica por la labor periodística y narrativa de Lizardi olvida con lamentable frecuencia que el Pensador, a lo largo de su trayectoria, cul-

3. Para Cedomil Goic, el Sueño de sueños (1792), del mexicano José Mariano Acosta, la Genealogía del Gil Blas de Santillana (1792), del también mexicano Bernardo María de Calzada, y el Evangelio en triunfo (1797), del peruano Pablo de Olavide, deben ser consideradas "las primeras novelas hispanoamericanas originales, veinte años anteriores a la obra de Lizardi” (1992: 372), a las que A. Chibán y E. Altuna (1989) añaden El desierto prodigioso, escrita hacia 1650, del santafereño Pedro de Solís. 
tivó también la poesía satírica, la fábula, los calendarios y el teatro, géneros que, como veremos, no sólo refrendan la unidad esencial de su obra, sino que arrojan luces oportunas para apreciar el carácter orgánico que rige el desplazamiento de unos a otros, con el fondo siempre del periodismo orientando los procedimientos retóricos y estilísticos, y los fines didácticos. Uno de sus últimos escritos, el Testamento, sintetiza los temas más frecuentados, las ideas políticas, sociales y educativas más acuciantes, las preocupaciones reformistas, las actitudes y los modos con que se abordan; y el que quiso fuera su epitafio («Aquí yacen las cenizas del Pensador Mexicano, que hizo lo que pudo por su patria») resume el espíritu combativo que animó su empresa y el cierto desencanto final que en ella acumuló.

Obviamente, para mejor comprender esta trayectoria y la envergadura de su empresa, con el trasfondo histórico omnipresente, la implicación permanente de la vida y la encarnación verbal resultante, se hace imprescindible tener en cuenta la transformación de las ideas y de las formas literarias que acompaña el periodo de la transición, con sus contradicciones inherentes y la lógica, por racional, ambigüedad de las actitudes. La transición, en efecto, pone en confrontación los «modelos históricos y lingüísticos del espacio» antiguo y moderno decisivos, en la perspectiva propuesta por Lotman (1982: 270 y ss.), para la subsiguiente modelización del espacio artístico. Tales modelos están ejemplificados de facto por la que Á. Rama (1984) y, en el caso concreto del Periquillo, M. Moraña (1989), ha denominado la ciudad letrada escrituraria, situada, en la época que nos ocupa, versus la ciudad de base implícitamente burguesa. Ello conlleva, práctica y pragmáticamente, contraponer a los ideólogos tradicionales del viejo orden, sobre todo de la Iglesia, la nueva clase de intelectuales orgánicos, que animados por los ideales ilustrados y la conformación de un estado moderno, estimulan medidas reformistas y proyectos utópicos. Se suscita de este modo la dialéctica tensionada de dos paradigmas, detentador y subvertidor respectivamente del orden establecido. La mentalidad colonialista, que persiste, y la conciencia(ción) nacionalista emergente, amparada aquélla en la lengua secreta como poder fáctico y abierta ésta otra al habla de la calle, se reflejarán en la distinta instrumentalización que hacen de los géneros literarios y, particularmente, del periodismo.

No procede entretenernos más de la cuenta; sí conviene insistir en que lo que antes era un espacio monolítico, se resquebraja ahora, presionado por las fuerzas de la innovación y la modernidad, conformando dos subespacios antinómicos con su correspondiente lenguaje, entendido éste, por decirlo con palabras de Bajtín (1989: 88-89), no como un conjunto de categorías gramaticales abstractas, sino como algo saturado ideológicamente. Frente a la figura tradicional del mecenas, 
frente a los principios fijos de la estética, frente a las modalidades discursivas estereotipadas, el lenguaje técnico y oscurantista, y el distanciamiento respecto a la realidad inmediata, se levantan los compradores modernos, el valor relativo y cambiante del gusto de los lectores, el ideal de la comunicación clara y la implicación, sub animo corrigendi, en la realidad circundante (Franco 1983). Hay, entre otras muchas que podrían citarse, algunas opiniones de Fernández de Lizardi que se antojan esclarecedoras al respecto; uno de sus más acérrimos detractores, Manuel Terán, le acusa de expresarse con la «grosería de taberna» y de novelar «en lenguaje de canalla», y el academicista Lacunza, figura destacada en el grupo purista de los «árcades», pide en el Diario de México (20-XII-1811) que se le corone como "Apolo y oráculo de los poetas que tienen su Parnaso en las banquetas de la plaza de esta capital", acogiéndose al precepto de Boileau de no ser literaria la palabra o expresión que daña al oído; el Pensador responde a éste en el folleto Quien llama al toro, sufra la cornada, editado por cuenta propia: "Sepa que quien le dio licencia a Cervantes, Quevedo, etc., etc., para usar en sus versos los dicharachos vulgares de su tiempo, me la dio también a mî"4. A Lizardi le interesa, pues, un lenguaje claro que conecte con el pueblo, objeto prioritario de su prédica reformista. Así lo manifiesta reiteradamente; por ejemplo, en el artículo "Vuelve Juanillo a visitar a su tío", de El Pensador Mexicano, pide el sobrino: "No cojamos las cosas tan de arriba; bajemos acá y hablemos a la pata la llana cuanto usted quiera (...); profanito, tío, profanito, y clarito, clarito, que nos entendemos bien" (Fernández de Lizardi 1968: 193-94); y esta claridad del lenguaje no se concibe como un fin en sí mismo, sino como un medio eficaz cara a sus pretensiones reformistas: "Nuestra conversación no es de lo más limpio", advierte el Sacristán al Payo en una de sus conversaciones, a lo que éste responde: "Es verdad, pero ella se dirige a la limpieza" (Fernández de Lizardi 1975: 79).

Ahora bien, las fronteras no son tan nítidas como acaso pueda inferirse. En el estadio autorial de producción, Fernández de Lizardi encontraba dificultades para escribir solamente en un lenguaje llano, pues, dado su novedoso status de escritor público, se veía obligado a desplegar sus conocimientos para demostrar su competencia; por ello, la chocarrería de la sátira y el refranillo, la frase de pulquería, el humor popular y el lenguaje cotidiano... contrastan (al margen de la dialogización que puedan suscitar) con la cita erudita y clásica; asimismo, promete lectores hechos unos "Demóstenes en elocuencia, Homeros en poesía, en filosofía Sócrates,

4. Para las citas supra referidas, así como para una síntesis de la polémica, véase J. Chencinsky (1963: 32-38). 
en legislación Solones...", pero acaba por darse cuenta de que anda "pedanteando y hablándoles en griego sin advertirlo” (Fernández de Lizardi 1975: 22). Pragmáticamente, pretende armonizar la eficacia del ejemplo vivo y del sermón hablado, es decir, de la transmisión oral, con la lectura, a la que la gente letrada concedía una gran importancia, lo que se resuelve con la alternancia de consejas y consejos, contrapesando, en su condición de escritor moralista, el placer de la narrativa con el discurso autoritario (Franco 1983: 17). En cuanto a la recepción de sus escritos, debe tenerse en cuenta el alto índice de analfabetos (de seis millones, sólo 30.000 saben leer y escribir), el perfil sociológico de lo lectores (ni los altos dignatarios ni las clases populares sumidas en la ignorancia, sino los criollos de mentalidad más abierta, como lo atestiguan las listas de suscriptores) y las tiradas de las obras, que oscilaban entre los 300 y 500 ejemplares. Acaso para subvertir las imposiciones de la escritura y ampliar el ámbito de recepción entre aquéllos a quienes desea instruir, es por lo que sugiere que el Periquillo se lea en voz alta, como viene a recomendar Pedro Sarmiento:

\begin{abstract}
"Cuando oyereis a uno que lee un sermón como quien predica, una historia como quien refiere, una comedia como quien representa, etc., de suerte que si cerráis los ojos os parece que estáis oyendo a un orador en un púlpito, a un individuo en un estrado, a un cómico en un teatro, etc., decid: éste sí lee bien" (Fernández de Lizardi 1997: 118-19).
\end{abstract}

La sugerencia, desde luego, se aviene con el caso, contado por él mismo en El Correo Semanario de México, de los obreros de una fábrica de puros que pagaban para que alguien les leyera los papeles del Pensador; pero, vistas las circunstancias supra referidas, este caso nos parece, como a Felipe Reyes (1982), conmovedor y excepcional.

Una cosa es cierta: Lizardi se posicionó frente al orden establecido, extra normas de la ciudad letrada; pero ésta, como Ángel Rama precisa, era no menos amurallada ni menos, sino más, agresiva y redentorista que la civitas colonial en que se asentaba, por lo que difícilmente había de consentir la deprecatoria apropiación de la escritura, la ilegalidad atentatoria del poder que regía el sistema (que lo digan la cárcel y la excomunión); de ahí que, aunque pone a luchar su pluma en favor de la libertad de imprenta, aunque Desvergüenzas y excomuniones no destruyen las sólidas razones, como pregona el título de uno de sus folletos, al final se manifieste con el ánimo claudicante y desencantado que refleja en su Testamento y despedida: "Dejo a los escritores la lección de que no se empeñen en defender los derechos de otros con demasiado calor, ni en combatir los abusos con energía, pues además de que adelantarán muy poco en tan grande empresa, se atraerán el odio de todos los 
criminales, y si éstos pudieren, no cesarán de perseguirlos" (Fernández de Lizardi 1982: 1124); pero también sabía que la ciudad letrada no había engullido tanto esfuerzo: “ ¿Qué ignorantes! -reta sobreponiéndose- ¿No advertís que, aunque yo muera, jamás faltarán escritores instruidos y resueltos que continuarán combatiendo los abusos?" (Fernández de Lizardi 1982: 1121-22). Indiscutible: la historia de la literatura mexicana así lo certifica.

Retomemos aquella grande empresa, iniciada a la manera de don Quijote y alentada hasta el mismo lecho de muerte, considerando las bases ideológicas que la fundamentan y estimulan, así como la naturaleza de los mecanismos formales desplegados en su obra y las razones de su funcionamiento. Fernández de Lizardi pertenece a esa nueva clase de intelectuales orgánicos que conforma un subespacio presionante versus el viejo orden de la ciudad letrada; que procura, desde una concepción moderna del estado, subvertir la antigua estructura colonial. La ideología que sustenta este empeño reformista, está inspirada en las ideas de la Ilustración, coincidencia generalizada (con mayor o menor énfasis, según los casos, en unos nombres u otros) entre los críticos que han estudiado la cuestión de las fuentes nutricias. Voy a entretenerme lo imprescindible en este punto, remitiendo, para consideraciones pormenorizadas, a la bibliografía correspondiente.

Conviene precisar, antes de nada, que las lecturas de Lizardi no son otras que las habituales de ese tiempo en Nueva España, según Ruth Wold (1970). Interesa tener presente, asimismo, que eran pocos los criollos que conocían y practicaban otro idioma (Seoane 1977), de ahí que los llamados «navíos de la Ilustración» llegaran a América en publicaciones traducidas al castellano. Y no conviene olvidar que la incipiente prensa española difunde el conocimiento de las ideas de Rousseau, Voltaire, etc. a través de los comentarios y recensiones de sus obras; en esta labor destaca el periódico El Pensador [1762], dirigido por Clavijo y Fajardo, con amplia difusión por todo el ámbito colonial. Ahora bien, sea cual fuere la procedencia, es innegable la relación de Lizardi con los ilustrados europeos; incluso se sabe que, a pesar de las prohibiciones, la literatura de los enciclopedistas europeos llegó y circuló profusamente por México; los nombres de Montesquieu, Rousseau, Voltaire, Marivaux, Milton, Fénelon, La Bruyère..., son autores ampliamente conocidos. Entre ellos, junto a la influencia de la doctrina rousseauana, hay que subrayar destacadamente la importancia de Feijoo (Spell 1926 y 1956; Ruiz Barrionuevo 1991; Polic-Bobic 1995). Pero el corpus de lecturas referido debe alargarse hasta la clasicidad. Las referencias incluidas en el artículo vienen ad hoc en nuestra ayuda según se infiere del siguiente fragmento: 
El escritor público se constituye un médico del público según sus luces, y no será buen médico el que, por contemporizar con las ideas extravagantes del enfermo, le administre dulces venenos en vez de bebidas saludables, sólo porque éstas son amargas e ingratas. ¡Pobres de Horacio, Juvenal, Persio, Ariosto, Boileau, Haller, Quevedo, Cervantes, Iriarte y otros muchos, si como escribieron sus sátiras en Roma, Italia, Francia, Inglaterra y España, las hubieran escrito en esta América. (Fernández de Lizardi 1968: 383).

Particularizando la tradición de la sátira en la literatura española, el Pensador nos suministra las lecturas más frecuentadas; en "Los paseos de la Verdad...", incluido en Alacena de Frioleras, precisa Lizardi (1970: 104): “(...) tenemos primorosos satíricos en España, tales como Quevedo, Cervantes, Villegas, Torres, Santos, Iriarte, Feijoo, Gil Blas (o el autor de esta novela), Amato y otros muchos que han merecido el aprecio de los doctos".

Además de los ilustrados y de los satíricos, ¿qué otros autores, centrándonos en el terreno de la ficción, se leían por esa época en la Colonia? Entre otros muchos pasajes, puede servirnos aquél del Periquillo en que el maestro discreto recomienda al padre del muchacho que

sería útil ponerme en las manos El hombre feliz, Los niños célebres, Las recreaciones del hombre sensible u otras obras semejantes; pero que nunca convenía que yo leyera Soledades de la vida, las novelas de Zayas, Guerras civiles de Granada, La historia de Carlo Magno y doce pares, ni otras boberas de esas, que lejos de formar, cooperan a corromper el espíritu de los niños (...), llenando su cabeza de fábulas, valentías y patrañas ridículas (Fernández de Lizardi 1997: 135-136).

Más sugestivo resulta el escrutinio realizado en la biblioteca familiar de la Quijotita, donde se mezclan algunos libros buenos y razonables con otros «perniciosos y de pésimo gusto», sin que se nos diga el calificativo que merecía cada uno:

Vea usted: tengo las novelas de doña María de Zayas, las Obras jocosas de Quevedo, las Aventuras de Gil Blas, la Pamela, el Eusebio, Novelas sin las vocales, la Clara, la Diana enamorada, la Atala, Alejo en su casita, Soledades de la vida y desengaños del mundo, Don Quijote de la Mancha y otros [...]. (Fernández de Lizardi 1979: 31).

Aun reconociendo la importancia de los clásicos españoles, según ha señalado Felipe Reyes Palacios, Lizardi no se apropia de ellos como quien sigue una tradición, sino que los incorpora a su bagaje erudito, asignándoles un lugar común. ¿Hay que ver en ello, siguiendo las pautas de González Obregón (1938), un cierto grado de ruptura con el yugo de serviles imitadores y una proclamación consi- 
guiente de originalidad literaria? En buena medida, ello supondría negar la perspectiva de la dependencia, que, sin embargo, acompaña el quehacer de tantos escritores posteriores y aun actuales; de hecho, la eficaz y personal utilización práctica y pragmática que hace de los modelos, se encamina teleológicamente a subvertir su propia incertidumbre y la de los demás en un periodo sometido a la conflictividad y las tensiones de la transición. Y la incertidumbre, sin duda, es la fuerza generatriz que activa ese proceso a la búsqueda de la identidad y la expresión propias; ¿habrá que recordar el doble vigor que reclama Henríquez Ureña (1978: 245-46) para imponer su tonalidad frente al rojo y el gualda? En buena parte por ello, a mi entender, deben recuperarse ciertos nombres, cuya obra, modos y estrategias filtra ilustradamente, y con doble vigor, si se quiere, el Pensador Mexicano.

No se trata de cuantificar influencias innegables a todas luces (Feijoo, Torres, Iriarte, Cadalso..., por lo demás, reiteradamente explicitadas por el propio Lizardi), sino de valorar cualitativamente, en la práctica discursiva, el magisterio de Quevedo, por ejemplo, en el uso del lenguaje cotidiano o en las posibilidades del sueño para la sátira; la lección cervantina, como veremos más detenidamente, en la intersección del carácter verdadero de la historia y la verdad en sentido poético, en la conformación de diversos espacios novelescos o en la refracción de la palabra irónica; y un tercer nombre, mencionado entre otros más por el Pensador y casi como de pasada por la crítica, el de Pedro Montegón y su Eusebio ${ }^{5}$ en lo que interesa a la técnica narrativa (el modo de entremeter las reflexiones del propio autor, directamente o por medio de personajes; las consecuencias que facilitan los episodios narrados; la técnica del viaje para generar múltiples episodios; la función de estos episodios cara a la tesis de la novela y al interés de los lectores; la explotación de elementos sentimentales para 'democratizar' sentimentalmente la percepción de lo bueno; las descripciones a veces rayanas en el trazo naturalista, el desplazamiento por los distintos niveles sociolingüísticos, etc.).

A partir de lo dicho, tres aspectos deben quedar claros: 1/ Como ha señalado M. Palacios Sierra (1965), la situación política del país obliga al mexicano a ser autodidacta; por ello, el interés por la educación se convierte en una de sus inquietudes principales como reformador y periodista; 2/ Fernández de Lizardi, en especularidad contigua con la ambigüedad mostrada durante la transición, sólo puede considerarse 'revolucionario' adjetiva y matizadamente, es decir, "en su calidad

5. Esta obra de Montegón, cuyos cuatro volúmenes aparecen entre 1786-88, fue en efecto un auténtico best-seller de la época -60.000 ejemplares hasta 1800-, estuvo censurada por la Inquisición (1790) y conoció una amplia difusión por todo el ámbito colonial. 
de mensajero, de propagador y defensor de ideas, no como originario de ellas" (Chencinsky 1963: 49); 3/ resulta más pertinente, en su caso, hablar de "innovaciones' en el sentido de incorporar como referente verbalizable y literaturizable la realidad mexicana inmediata, de utilizar el lenguaje popular y términos mexicanos o de introducir, con toda su carga decisiva, la novela en América (Martínez 1955: 26; Reyes 1975:143). Pero, desde la perspectiva que ahora nos ocupa, teniendo como fondo las fuentes mencionadas, interesa subrayar que Lizardi amplía, en efecto, y culmina "ciertas posibilidades de expresión, no al descubrirlas o renovarlas, sino al concretar sus potencialidades como vehículos literarios", según J. Chencinsky (1963: 50). Es en esta dimensión donde cobra toda su importancia práctica y pragmática el periodismo y, en su órbita, los diversos géneros, utilizados por ser literariamente útiles y ser también útiles socialmente.

No descubrimos nada nuevo; la literatura hispanoamericana del siglo XIX aparece preferentemente en periódicos y revistas por diversas causas, entre las que B G. Carter (1968) señala la censura, más fácilmente aplicable a los libros, la escasez del papel (de hecho es una de las razones por las que El Pensador Mexicano, según el propio Lizardi, se publica en tres etapas), la inestabilidad política y económica, el gusto de los hispanoamericanos por los géneros breves: cuentos, cuadros de costumbres, fábulas, ensayos, etc. Un simple detalle: en 15 años, de 1812 a 1827, Lizardi promueve ocho periódicos y, ateniéndonos a las cifras facilitadas por Henríquez Ureña (1947), Velasco Valdés (1955) y Ruiz Castañeda (1974), sólo durante el periodo insurgente (1810-1821) hay 15 órganos de prensa en México capital y 40 , en conjunto, en el país. Las cifras, como puede deducirse, son elocuentes. No es difícil suponer, asimismo, que esta vitalidad reproduce la tensión de los subespacios ideológicos confrontados; por ejemplo, con El Ilustrador Nacional, fundado en 1811 por Morelos para alentar la causa independentista, polemiza, desde las convicciones realistas, El verdadero Ilustrador Americano, creado el mismo año por Beristáin; o, centrándonos en el no menos polémico ámbito de la religión, contra las ideas reformistas del periódico Hay va ese hueso que roer y que le metan diente reacciona El quebrantahuesos. Recordemos, con Alfonso Reyes (1975: 143), que es ésta una época de escaso valor artístico, pero de mucha letradura, de mucho ambiente y vitalidad; y que en ella sobresale, como figura central, José Joaquín Fernández de Lizardi. Las condiciones, pues, para que el Pensador Mexicano se decante por el periodismo, se nos antojan meridianamente claras; más aún si consideramos su estatuto de ideólogo moderno y que las posibilidades de un medio tan directo, inmediato y eficaz como el periódico convenían estratégicamente al ideal de la comunicación clara y a la divulgación de sus objetivos ilustrados. 
Precisamente por ilustrado, es decir, por reformista y educador, Lizardi veía con recelo las posibilidades críticas, moralizantes o estrictamente didácticas de la literatura de ficción. Ahora bien, para determinar la contextura específica del discurso, no sólo conviene tener en cuenta quién habla, su situación y la intención que lo anima, sino además saber a quién se dirige. La tipología del lector lizardiano es la del criollo que no ha pasado por las aulas universitarias o, más generalmente, por decirlo con palabras de su enemigo José María Aza, «el aguador, la cocinera, el muchacho, quienes por lo común sólo se diferencian de los brutos en la cualidad risible, usando de este atributo [...] poquísimas veces con fundamento»; añádanse los "que acaso seréis, algunos, plebeyos, indios, mulatos, negros, viciosos, tontos y majaderos", mencionados en el «Prólogo, dedicatoria y advertencias a los lectores» del Periquillo, a quienes elige como los "únicos mecenas y protectores de cuantos mamarrachos escribiere" (Fernández de Lizardi 1997: 94-95). En consecuencia, Lizardi, atento a las exigencias de novedades y a las necesidades de educación de estos lectores compradores, procura complacer su gusto por lo heterogéneo y lo sensacional, las noticias contemporáneas, la prosa divertida y ligera de..., naturalmente, el periódico, medio a su vez de subsistencia. No sorprende, por ello, que escandalizara a sus contemporáneos con sus polémicas sobre las condiciones de la producción literaria, las reivindicaciones de paga por sus escritos y su dependencia del mercado ${ }^{6}$; y que los aferrados entre éstos a los criterios puristas del gusto, lo acusaran de escribir por dinero, de rebajarse al nivel de tal público, de usar la «frase de pulquería» y la «grosería de taberna», y de ser «el primero en novelar en lenguaje de canalla» ${ }^{7}$.

Si consideramos, pues, que quien habla es un ilustrado, que la situación en que habla está tensionada por la transición de la estructura colonial al estado moderno, que sus intenciones son educativas (Álvarez de Testa, 1994) y que se dirige, sin desdeñar otros ámbitos, a los pobrecitos de la plebe con voluntad de ser entendido; si, insistimos, recela de la efectividad didáctica de los géneros de ficción, decantándose

6. Sorprende a Lizardi que los libros no paguen impuestos y que el escritor no reciba una paga por sus escritos; defiende, en consecuencia, que al igual que "el que sirve al altar come del altar, el que sirve al público debe comer del público. Nadie nota que se le pague al orador su sermón, al abogado su alegato, al médico su curación, ni que se ha de llevar a mal que al autor se le pague su trabajo" (Fernández de Lizardi 1968: 155).

7. Comenta al respecto L G. Urbina: "Su estilo es llano hasta la chabacanería; su tendencia a la observación y la imagen naturalistas, lo lleva a ser exacto hasta la grosería. Los diálogos (...) están copiados con tanta propiedad que el léxico usado en ellos se halla recubierto de modismos y vocablos regionales; el lenguaje del pueblo está trasladado con fidelidad, con verdad, pero sin arte, sin artificio alguno, sin gusto" (1965: 74). Para la respuesta de Lizardi a sus detractores, véase su Apología de «El Periquillo Sarniento» (Fernández de Lizardi 1982a: 17-27). 
por las prácticas discursivas más próximas a la eficacia de la comunicación clara y de la lengua hablada, se comprenderá que recurra al sermón, al proyecto, al diálogo, a la biografía ejemplar, la sátira, la fábula y el epigrama gracias a las posibilidades didácticas que ofrecen. El periódico, así, viene a ser con frecuencia un simple cauce, fungible y perecedero, que acoge los distintos géneros y modalidades genéricas en uso $^{8}$, al tiempo que impregna tales géneros cuando se cultivan fuera de su cauce; es lo que ocurre, por ejemplo, con la novela, situada inicialmente versus los géneros educativos por su componente ficticio, pero diestramente reconducida hacia los fines educativos gracias a la instrucción suministrada por la anécdota que, por mirarse, opera como ejemplo vivo y, además, aviva con su amenidad la atención del lector. A fin de cuentas, la interrelación de periodismo y literatura responde a la misma estrategia comunicativa, como señala oportunamente J. I. Gutiérrez:

Las fronteras entre lo literario y lo no literario son cada vez más borrosas, sin duda Y no siempre porque el periodismo -en concreto- pretenda acercarse a la literatura sino porque la literatura se ha ido aproximando en sus géneros "mayores" (como la novela) a otros discursos, entre ellos el discurso periodístico. Literatura y periodismo son dos modos de hacer paralelos -algunas veces convergentes-, cuya coincidencia fundamental es la de utilizar la palabra como utensilio de trabajo y la frase como vehículo del pensamiento. (1999: 88).

Esto nos permite extraer entre otras conclusiones, en primer lugar, la incuestionable importancia del periodismo para comprender la producción, la dimensión y la proyección del Pensador Mexicano. Lo han puesto de relieve Urbina (1965), Azuela (1947), Yáñez (1955) y R. Oviedo (1982a), entre otros; Henríquez Ureña (1947) ha reclamado un estudio pormenorizado; pero, a pesar de todo, salvo los trabajos introductorios a las Obras de J. Chencinsky y Ma ${ }^{\text {a }}$ R. Palazón, y los monográficos de Margarita Palacios Sierra y Rocío Oviedo, las referencias al periodismo son tangenciales. En segundo lugar, la mayoría de los críticos viene percibiendo las constantes de intención que vinculan los diversos géneros literarios cultivados por Lizardi (poesía satírica, fábula, periodismo, novela, teatro...); este hecho, sin embargo, no se ha valorado plenamente en perjuicio "de una visión uni-

8. Como indica $\mathrm{M}^{\mathrm{a}}$. R. Palazón, el periódico, al igual que el folleto, "era una mezcolanza de géneros, un recorrer la prosa y la poesía, los diálogos, las narraciones breves de temas moralistas y los comentarios editoriales, a los que se añadían avisos, noticias y composiciones que se remitían" (1981: X); en cuanto a las razones que favorecen la elección de tales géneros, escribe J. Franco lo siguiente: "En la escala de la efectividad el ejemplo vivo y el sermón hablado tenían más fuerza que la escritura. De ahí la preferencia de la época por los géneros que imitaran las formas ya institucionalizadas de la comunicación hablada" (1983:5). 
taria, orgánica del conjunto", como indica Chencinsky (1963: 18)9 . En tercer lugar, por simple inercia, como ocurre en otros aspectos, se vienen repitiendo conceptos y visiones sobre la trayectoria literaria de Lizardi que distorsionan gravemente, desde la perspectiva genérica y la intencionalidad ilustrada, esa visión global y el proceso orgánico de toda su obra. Dicho de forma sucinta: la producción de Lizardi suele distribuirse en tres etapas, separadas por la repercusión de la censura, que fuerza su paso desde el periodismo (1812-16) a la novela (1816-20) y de ésta, nuevamente, al periodismo; da la impresión, con más frecuencia de la deseable, de que Lizardi no ha escrito más. Pero la cosa no es tan simple: atendiendo a los géneros, en el sentido institucional del término, el Pensador también escribe poesía y teatro; más aún, las circunstancias externas deben ser matizadas; la libertad de imprenta se suprime en diciembre de 1812 y en 1814 se restablece la Inquisición; sin embargo, ello no impide que Lizardi (mediatizado, claro está) continúe su labor periodística hasta julio de 1816 (último núm. de los Cajoncitos de la Alacena); por el otro lado, es cierto que en febrero de 1820 tiene la aprobación para publicar el Catrín y no lo hace; alegar para ello que, al recuperarse los derechos constitucionales ese mismo año, se vuelca de lleno en el periodismo (El Conductor Eléctrico), nos parece una razón tan evidentemente externa como literariamente insatisfactoria y secundaria. Si se cree que Lizardi utiliza la novela como excusa para evadir la censura, se comprende mejor, como piensa Rocío Oviedo, que sea para él "primordial la manifestación de sus opiniones adecuando éstas a la ficción y no viceversa" (1982b: 5). De este modo, al ponerse la ficción al servicio de sus ideas, se explica más fácilmente que entre y salga de ella (presionado incluso por agentes externos como la censura o la carestía de papel) en términos retórica, pragmática y éticamente útiles (Estévez, 1995). Para ello conviene tener en cuenta que en las distintas etapas, es decir, sincrónicamente, coexisten géneros diversos: la poesía satírica y la fábula con el periodismo, en la primera fase; en la segunda, junto a las novelas, los calendarios a la manera de Torres y la edición en volumen exento de las Fábulas; en la tercera, además de los periódicos y los folletos, el teatro. Sin desdeñar, pues, motivaciones secundarias (la censura) o la funcionalidad oportuna y hasta oportunista de la ficción novelesca, se impone considerar la obra de Lizardi como una trayectoria e inscribir en ella, diacrónicamente, la evolución tan literariamente orgánica como didácticamente ilustrada de los géneros, siempre con el

9. Mucha culpa de ello se debe, creemos, a la desigual atención crítica concedida a los diferentes géneros; una simple ojeada a la bibliografía sobre Fernández de Lizardi así lo denuncia; es poca la atención prestada al periodismo por contraste con la novela y, dentro de ésta, casi toda la concita el Periquillo. Esa visión orgánica es lo que, en alguna medida, pretendemos destacar con el presente trabajo. 
periodismo como orientador explícito o implícito: a la poesía satírica y a la fábula (ejemplo general por cuanto critica vicios y costumbres, no personas) sigue la novela (ejemplo directo proporcionado por las historias particulares), y a ésta, el teatro, donde el ejemplo vivo se resuelve en comunicación directa al hacerse la palabra carne en el escenario. Creemos, pues, que la obra de Lizardi debe estudiarse, en su globalidad, como un proceso orgánico, estimulado por la eficacia comunicativa. Se aprecian entonces, más clara y literariamente, las constantes de intención que vinculan los diversos géneros cultivados; y de inmediato se percibe, cuando se cotejan entre sí, incluso sin esforzar la atención, que se trata de estructuras superficiales distintas para formalizar una misma estructura profunda.

Uno de los entuertos que procede deshacer es la creencia rutinaria de que $\mathrm{Li}$ zardi adopta la ficción novelesca como medio para implicarse, disimulando respecto a factores extraliterarios. Es obvio que Lizardi simula para disimular (por ejemplo, proyectos utópicos) o disimula simulando fingidamente (por ejemplo, las novelas), según los casos. Esto es algo que, con anterioridad al Periquillo, el Pensador ha practicado reiteradamente. Digámoslo de modo tan abierto como sintético: mientras que, en lo concerniente a la diversidad de temas abordados, no existen fronteras, pues los mismos temas se vehiculan con las formas, técnicas y modos más variados, en el nivel formal es una constante la permeabilidad de los límites que constituyen marcas paradigmáticas pertinentes, y no tanto (que también) a los efectos de la contaminatio (géneros que a veces se cruzan y entreveran), cuanto por el tránsito gradual de unos a otros, de unos moldes (el periódico) a otros cauces (la novela e incluso el teatro). Por lo demás, sea cual sea el tema objeto de interés y el molde genérico en que se formaliza, en todo momento el texto se ofrece como un campo de batalla problematizado por las oposiciones antinómicas y la confrontación, cuando no la dialogización subsiguiente. Pero, bajo los efectos de sentido que el plurilingüismo pueda suscitar, procede analizar la obra de Lizardi considerando las relaciones intertextuales que en ella se entrecruzan, así como, en perspectiva genérica y pragmática más amplia, la vinculación de los contenidos a determinadas formas preferentes.

Dice Lotman que cada obra es una modelización particular de esa gran texto en que consiste la cultura en general ${ }^{10}$. Precisamos más aún, teniendo en cuenta la

10. Escribe en este sentido Y. M. Lotman: "Los modelos históricos y lingüísticos nacionales del espacio se convierten en la base organizadora para la construcción de una «imagen del mundo», un modelo ideológico global propio de un tipo de cultura dado. Sobre el fondo de esas construcciones adquieren significado los modelos espaciales particulares creados por un texto o grupos de textos dados" (1982: 272). 
incertidumbre y la titubeante búsqueda de la identidad y de la expresión propias (digamos, retrotrayendo las inquietudes de Carlos Fuentes, de la mexicanidad y el lenguaje), que estimulan a Lizardi en unas circunstancias muy precisas: los modelos históricos y lingüísticos del espacio mexicano en el periodo de la transición, particularmente reflejados en el espacio artístico, supra géneros, de la obra lizardiana. Ni el aspecto más aparentemente trivial ni el código más humilde parecen escapar a su atención si en ello aprecia alguna marca de utilidad pública. Dedúzcase, pues, que la diversidad referencial y, por lo tanto, de referentes temáticos, es un hecho. Ahora bien, podemos sistematizarlos en tres grandes bloques temáticos, siguiendo las orientaciones de R. Oviedo (1982b: 311). Encontramos en un primer bloque los temas de carácter político, religioso y social que concitan, desde diversas perspectivas, las bondades y miserias de los poderes civil y eclesiástico, así como la problemática social y económica (costumbres, familia, monopolios, profesiones...), abarcando una tipología variadísima. Tenemos, en segundo lugar, la preocupación por América y el hombre americano, que acaba conformándose en teoría. Lizardi se enfrenta a la opinión europea desprestigiadora de América (Buffon, Hume, Voltaire y, sobre todo, el abate Raynal: inferioridad y debilidad del americano por vivir en un clima cálido, poca inteligencia, condición de salvajes degenerados...). Las opiniones positivas de Humboldt, aliadas a la concepción rousseauana del «buen salvaje», cambiarán la consideración inicial; este bloque temático conecta con el anterior en relación de causa a efecto: “¿Qué se podrá esperar en América donde, aunque abundan los talentos, escasean los medios para cultivarlos?", pregunta Lizardi; la respuesta queda en gran manera objetivada al admitir que "tienen capacidad y talento [...] para aprender cuanto hace el más hábil de otra nación, para imitarlo y aun excederlo", lo que se reafirma con la siguiente interrogación retórica: “¿qué fueran provistos de buenos libros, auxiliados de doctas escuelas y estimulados con grandes premios?" (Fernández de Lizardi 1968: 162). Entramos, contiguamente, en uno de los temas predilectos del Pensador: la educación, inexorablemente conectada a las condiciones que actúan sobre el hombre y el espacio americano: "La falta de educación nace de la pobreza, la pobreza refuerza y perpetúa la ignorancia"11. Esto nos introduce en el tercero de los grandes bloques temáticos conformados, referido a la literatura como modus operandi, que aglutina toda una serie de motivos temáticos objeto de hondas preocupaciones (y

11. Y, en contigüidad, escribe Fernández de Lizardi en El Payaso de los Periódicos: "La ignorancia no produce sino esclavitud y desgracias, así como la ilustración es fuente de la libertad, abundancia y felicidades. Según este principio, vemos que la gente más ignorante de los pueblos, o de lo que se llama plebe, es la más pobre, la más viciosa y también la más a propósito para ser esclava” (1975: 23). 
hasta de disgustos): la libertad de expresión, las teorías sobre lo literario, las polémicas con sus detractores, sus opiniones sobre la prensa, etc.

Pero, más allá de compartimentos estáticos, la verdad es que todos los aspectos de la realidad contemporánea mexicana, sea como temas nucleares o como motivos secundarios, discurren por toda su obra, desde El Pensador Mexicano hasta El Correo Semanario de México, anegando la poesía satírica, las fábulas, las novelas y el teatro sin fronteras formales que obstaculicen su fluir. Algunos ejemplos, diversificando géneros y cauces, pueden corroborar lo dicho: la educación se aborda, entre otros muchos momentos, en El Pensador Mexicano (t. I, núm. 13; t. II, núms. 7, 8 y 9) ${ }^{12}$, en el núm. XIII de la Alacena con el artículo "Sobre la educación popular" (Fernández de Lizardi 1975: 73-77), en no pocos pasajes del Periquillo, de la Quijotita y del Catrín, en El Conductor Eléctrico, en el Unipersonal del arcabuceado, en las Conversaciones del Payo y el Sacristán y, para no entretenernos, en el folleto Sociedad pública de lectura (Fernández de Lizardi 1982b: 882-84). En este nivel de los contenidos, la intratextualidad es un fenómeno reiterado, como puede verse en las referencias a la tan extendida costumbre del juego ${ }^{13}$, a la experiencia de la cárcel ${ }^{14}$, a la descripción del tópico naufragio que propicia la llegada a los espacios utópicos de Ricamea y Saucheofú ${ }^{15}$ o, en fin, a la esclavitud (episodio del Periquillo, t. IV, cap. 4, pág. 722 y ss., y el drama El negro sensible); simples ejemplos, entre muchos posibles. Ahora bien, más que un inventario exhaustivo, conviene destacar los ideales básicos que articulan los diversos paradigmas temáticos y que estimulan la actuación del Pensador; me refiero, siguiendo a Felipe Reyes, a

la confianza sin límites en el potencial transformador que la libertad de expresión y la educación conllevan, y la elección de la legalidad como medio para llevar a cabo las reformas que demanda el país. Tratándose de estos ideales, su entusiasmo le lleva fácilmente a la utopía”. (1982a: XXIX)

12. Nos referimos a sus artículos "Educación" y "Proyecto fácil y utilísimo a nuestra sociedad" (Fernández de Lizardi (1968: 106 y ss. y 419-37, respectivamente).

13. Cotéjense al efecto los respectivos fragmentos de "Los consejos de Birján a sus discípulos nuevos" y de "Continúa Birján sus lecciones" (Fernández de Lizardi 1970: 79-89) con otros de El Periquillo Sarniento (Fernández de Lizardi 1997: 354-71) y de Don Catrín de la Fachenda (Fernández de Lizardi 2001: 107-108).

14. Véanse ad hoc los pasajes respectivos de Fernández de Lizardi en Don Catrín de la Fachenda (2001: 107-108) y en la Carta Segunda del Pensador al Papista, en El Sol, 7 de mayo de 1822, págs. 14-16.

15. Son de una gran similitud las descripciones que hace Lizardi en "Continúa la carta de mi hermano", en El Pensador Mexicano (Fernández de Lizardi 1968: 747-48). 
El tránsito es tan lógicamente comprensible como orgánicamente literario. $\mathrm{Si}$, por una parte, la necesidad de reformas implica el diagnóstico previo de una realidad enferma, los proyectos y ficciones utópicas, por otra, bajo la apariencia del reverso de esa realidad, operan como medios críticos que denuncian indirectamente la verdad objetiva ${ }^{16}$. De la mano de los proyectos y la ficción utópica, propuestas, en cualquier caso, antinómicas a los referentes temáticos del antiguo orden, entramos en los (sub)géneros y las estrategias técnicas con que se formalizan los diversos contenidos ${ }^{17}$.

Al igual que los temas más diversos transitan por el espacio artístico lizardiano sin fronteras que lo obstaculicen, los mecanismos formales, esto es, los paradigmas genéricos y las estrategias técnicas que los activan, están separados por límites tan permeables que facilitan no sólo los efectos de la contaminatio, sino también, en perspectiva de trayectoria, el tránsito por los diversos cauces y moldes. Quiero decir que Lizardi no sólo llega a la novela presionado por factores extratextuales, en todo caso secundarios y externos, sino también como resultado, procesal y orgánicamente literario, de implicaciones y (di)simulaciones previas. Cuando se justifica, incluso literariamente, la adopción de la novela y, en particular de la técnica autobiográfica, porque permite dar cabida a géneros diversos (el diálogo, el sermón, la alegoría, la sátira, la fábula, el proyecto utópico, la biografía ejemplar...), no suele tenerse en cuenta que tales géneros y subgéneros ya habían sido y aún habrán de ser cultivados en el cauce del periódico; como también lo habían sido y aun

16. Indica $\mathrm{M}^{\mathrm{a}}$. R. Palazón que Lizardi recurre para canalizar su denuncia a "recursos tales como fábulas, teatro, folletos o periódicos cuya tónica consiste en alusiones directas contra los sistemas reinantes, o indirectas, esto es, paraísos artificiales que toman la apariencia del reverso de la verdad social y, sin embargo, son especulaciones utópicas que hacen las veces de medio para clavar el colmillo en la verdad objetiva" (1970: 9).

17. Aunque será objeto de otro artículo, viene a cuento anticipar la distinción entre género y modalidad en lo que interesa a las utopías lizardianas. Entendemos, con Fernando Aínsa (1984), que el concepto 'utopía' aparece conectado a disciplinas muy diversas, lo que contribuye a enriquecer su significado en la misma medida que lo difumina hasta adquirir en su dispersión connotaciones peyorativas. Frente al sustantivo, nos parece más pertinente y significativo el empleo del adjetivo 'utópico', con el que la utopía traduce un estado de ánimo sinónimo de actitud rebelde, de oposición o resistencia al orden establecido, lo que se aviene con el ideal ilustrado y pone en confrontación lo antiguo con la pretensión de un estado moderno. De igual manera, frente al concepto de género que diseña la Utopía [1516] de Tomás Moro al poco de su publicación, preferimos el de modalidad (es decir, con un carácter adjetivo y un alcance parcialmente estructural) entendida así como la facultad de imaginar, de modificar lo real por la hipótesis, de crear un orden diferente al establecido, que no conlleva una negación de lo real, sino una profundización de lo que podría ser. Por lo pronto, lo utópico, en el uso de Lizardi, conviene a los proyectos y a las ficciones así adjetivados, y en ambos casos subvierte su sentido hasta la posibilidad de su degradación; cfr. al respecto Jacques Joset (1983: 353-68) y Luis Sáinz de Medrano (1989: 77-83). 
después lo serán no pocos de los procedimientos técnicos que facilitan el juego de los (di)simulaciones ficcionales.

En efecto, es fácil documentar el género narrativo ya en el t. I, núm. 11 de $E l$ Pensador Mexicano: el viaje con la Experiencia en el carro del Tiempo por «espacios [no tan] imaginarios» (Fernández de Lizardi 1968: 97-102); en el T. III, núms. 2, 3 y 4, el relato primopersonal del supuesto hermano del Pensador (Fernández de Lizardi 1968: 385-99) o en los núms. 18 al 22 de Alacena de Frioleras, los "Paseos de la Verdad. A imitación de los que el doctor Villarroel hizo entre sueños con el fantasma de don Francisco de Quevedo" (Fernández de Lizardi 1970: 103-124). El salto desde aquí a la novela no nos parece, pues, tan brusco. Como ocurre asimismo en lo que concierne al teatro, prefigurado ya en el "Pleito de las calaveras" incluido en los Suplementos del Pensador, auténtica pieza teatral breve (o forma semidramática, cuando menos) con indicador de acción incluido: "Hacen que se toman los votos, y que se ven tantos a tantos" (Fernández de Lizardi 1968: 321-29)18; por estas fechas escribe el Auto mariano para representar la aparición milagrosa de nuestra madre y señora de Guadalupe. El cauce del periódico, además, diversifica otros subgéneros que posteriormente la novela integrará al amparo de las posibilidades que brinda al efecto la técnica autobiográfica; así, por ejemplo, el diálogo de tradición humanista (conducido por el esquema bipolar vetus/puer), antes de aparecer en los diálogos de Periquillo Sarniento con los experimentados y discretos don Antonio, en la cárcel, y el coronel, en Manila (Fernández de Lizardi 1997: 389 y ss. y 687 y ss., respectivamente) o en la conversación de don Catrín con su tío el cura (Fernández de Lizardi 2001: 71-74), ha sido utilizado reiteradamente con el tío Toribio y Juanillo su sobrino (Fernández de Lizardi 1968: 71 y ss.), en "El egoísta y su maestro" (Fernández de Lizardi 1968: 293-96) o entre el ranchero y su hijo (Fernández de Lizardi 1970: 3944); la fábula esópica (La abeja y el zángano, El cacomixtle y la gallina, El mono y el perico, La rata moribunda, etc.) tendrá su continuidad en la de los cangrejos y la del león, en el Periquillo; la prédica sermonaria, los entretenimientos digresivos y los tonos admonitorios, que se hacen insufribles en el Periquillo y la Quijotita, que afloran incluso en el Catrín e impregnan el tono ensayístico de los Unipersonales, han sido ya utilizados en El Pensador y en Alacena de Frioleras $^{19}$.

18. Rocío Oviedo indica que el Pleito "presenta todos los elementos característicos de una obra teatral. En este sentido Lizardi es el primer autor (y quizás el único) que presenta una obra de teatro dentro de un periódico; más concretamente por su extensión sería un entremés" (1982b: 688).

19. Pueden servir de ejemplo los escritos siguientes: "Sobre la exaltación de la nación española y abatimiento del antiguo despotismo", "Sobre el amor de la patria" o "Mi vindicación" (Fernández de Lizardi 1968: 47-69, 379-84 y 439 y ss., respectivamente) y "Los consejos de Birján a sus discípulos..." (Fernández de Lizardi 1970: 79-89). 
Como en el caso de los contenidos, el fenómeno de la intratextualidad es fácilmente apreciable en el estadio de las formas, lo que no debe sorprender en un universo como el lizardiano que, junto a las permanentes conexiones con el campo de referencia externo, proporciona frecuentes guiños autorreferenciales; es el caso de ese lector preocupado que, por conocer las ideas de Pensador sobre la educación (t. I), envía un "Comunicado" (t. II) a favor de una señorita que desea instruir niñas; la nota $e$, (t. II), cap. 1, pág. 308, del Periquillo sobre la educación, remite a los números 7-8-9 (t. III) de El Pensador Mexicano, donde se ha presentado el "Proyecto fácil y utilísimo a nuestra sociedad"; los preliminares de la Quijotita tienen como referencia inmediata y explícita al Periquillo, y con el tal Sarniento, al que llama su amigo, quiere competir don Catrín de la Fachenda; por no hablar, en fin, de las muchas consideraciones metaliterarias y metacríticas que Lizardi considera oportuno realizar al hilo de las polémicas en que se ve envuelto o de las atenciones que se le reclaman.

La misma permeabilidad puede advertirse cuando se escudriñan las estrategias técnicas desplegadas. En forma primopersonal están narrados el viaje que realiza con la Experiencia, los "Paseos de la Verdad", las cartas de su hermano, así como el Periquillo y el Catrín; verdad es que, en unas ocasiones, esa primera persona coincide con la del Pensador mientras que, en otras (las cartas del hermano, el Periquillo...), es una primera persona ajena; pero, en todos los casos, constituyen ardides que contribuyen a lo que Díaz-Migoyo ha llamado la ironía de lo novelesco ${ }^{20}$. En otras ocasiones se protege tras la visión foránea, como en el ya mencionado Diálogo entre un francés y un italiano sobre la América septentrional (con Goldsmith, Montesquieu y Cadalso al fondo), para así objetivar la realidad enjuiciada; o finge recibir comunicados anónimos (de «El ciudadano pobre», de «La voz del pueblo», de «José... lo demás no lo diré», etc.), a los que responde, descubriendo el estilo de tales respuestas la auténtica autoría de aquellos comunicados, etc.

Pero, transcendiendo la perspectiva inmanente (en la que, por cierto, cabría destacar el paralelismo apreciable en el estatuto del narratario, $v . g$., en "Los consejos de Birján...” y en el Periquillo, en ambos casos los hijos), acaso sea más importante atender a la posición del autor con respecto a su obra. En este sentido, Fernández de Lizardi configura distintos espacios ficcionales que propician, cara

20. Gonzalo Díaz-Migoyo así lo explica: "Quede claro [...] que esta «ironía de lo novelesco» no es la ironía del narrador respecto de su relato, y mucho menos la ironía de los personajes o de los sucesos relatados, sino la del novelista al mencionarle irónicamente al lector cierta situación narrativa; es decir, al presentársela como real al tiempo que le indica que no lo es" (1990: 154). 
a sus implicaciones y (di)simulaciones, el juego perspectivista del distanciamiento gracias al ardid de la palabra ajena, cuando no al juego interpuesto de las voces. El ejemplo más evidente lo encontramos en el Periquillo Sarniento y, en buena parte, hay que conectarlo con la ficción (todo lo tradicional que se quiera) del manuscrito, lo que permite al Pensador introducirse en la historia desde la que, gracias a la amistad entablada con Pedro Sarmiento, pasa a la instancia de la narración, continuando a la muerte de éste el capítulo VIII y enteramente el IX (t. V); y de la ficción, instancias de la historia y del discurso, al relato que se lee, en el que ha metido mano ordenando, corrigiendo y anotando los cuadernos, para llevarnos finalmente a la realidad extradiegética en calidad de editor. Este juego perspectivista del distanciamiento, sobrevolando la realidad inmediata desde los espacios ficcionales superpuestos y enjuiciándola a través de las voces interpuestas para implicarse en ella (di)simuladamente, puede apreciarse en los distintos géneros, subgéneros o modalidades más frecuentadas; por ejemplo, en la tradición de la sátira (la menipea de Luciano más el sermo milesio de Apuleyo, ya mezclada a mediados del XVI, en la línea de Erasmo, Cervantes, Quevedo, Torres, Iriarte..., y fácilmente detectada por el lector culto de la época), en el subterfugio del sueño (el viaje con la Experiencia, el folleto Si dura más el congreso nos quedamos sin camisa...) o de la transformación (El hermano del perico que cantaba la Victoria) y en el cauce ya visto del diálogo humanista.

En el caso del viaje, después de dar vuelta a sus pensamientos "para entretener los ratos ociosos y las amarguras de mi soledad", y luego de "cenar a lo loco", nuestro Pensador se queda dormido como un lirón (espacio $1^{\circ}$ ); al poco, una nube lo acoge en su seno y lo asciende hasta el carro del Tiempo, que lo desplaza por los "espacios imaginarios" junto a la Experiencia, la cual le va mostrando una amplia fauna de locos; finalmente se despiden, el carro se vuelca y él cae al patio del hospital que había visitado horas antes, despertándose con el golpe de la caída de ese $2^{\circ}$ espacio a la realidad de verse, asustado, pero sano y salvo, en su cama; el subterfugio no le salva de la cárcel por el folleto en el que "fingí un sueño y que un congreso de ladrones cuchareros discutían sobre el modo de robarnos..." ${ }^{21}$. En el caso de El hermano del perico..., el primer nivel de la diéresis, contiguo a la realidad extratextual, nos presenta a una mujer que quiere vender un perico al Pensador; éste se resiste, pero finalmente lo acepta a prueba; tras "comer, y sobre siesta" (subrayo la intertextualidad del tópico), mantiene con el loro un diálogo en el que éste le confiesa que el dueño primero del alma que lo anima no es otro que Pitágoras; como

21. Aparecido en $E l$ Sol, febrero de 1823. 
puede deducirse, pasan repaso a los más diversos temas hasta que la entrada de la mujer que lo había vendido, deseosa de cobrar los cuatro pesos acordados, nos baja al primer nivel; por supuesto, el Pensador compra el perico y, en el diálogo siguiente, ya no es necesario estar dormido para que la ficción siga su curso. La diversificación de espacios ficcionales se aprecia asimismo en el relato primopersonal de su hermano: Lizardi comienza presentándose a sí mismo como un personaje preocupado por no encontrar materia para el número siguiente de su periódico; un negrito, tan folclóricamente providencial como exóticamente prefigurador, le entrega una carta de un supuesto hermano (de nombre Antoñito, pero que firma Manuel), quien le facilita no sólo la materia, sino el espacio ficticio, además de interponer su voz para refractar (di)simuladamente la realidad inmediata; el negrito, por cierto, se llama (es un) pensamiento. En fin, ¿no encontramos la misma estrategia en las Conversaciones del Payo y el Sacristán? Lizardi, como maese Pedro (el diálogo con Cervantes y sobre todo con el Quijote, lectura dieciochesca al margen, es permanente), maneja las figuras que dialogan en el artificio ficticio creado $\left(2^{\circ}\right.$ nivel $)$, al que accede Lizardi desde un primer estadio ficticio insertando de motu propio notas y comunicados o bien otros escritos con noticias de actualidad que el Sacristán y el Payo creen oportuno comentar; pero aún ascendemos a un nivel más alto cuando estas figuras del «retablo» se remontan desde el nivel que le es propio al de una república imaginaria mediante su "Proyecto de Constitución para..."; el último diálogo nos proporciona aún otra clave: es un sueño. El perspectivismo se observa asimismo en el teatro, pues las figuras de Celestino Ramírez y de Agustín Iturbide, en los unipersonales respectivos, o del padre Arenas en la farsa alegórica que nos ofrece su drama, son tan sólo voces interpuestas entre el público y el autor para reproducir, en una mezcla de ensayo y reportaje periodístico, los comentarios y reflexiones de Lizardi sobre la educación, el poder civil y los peligros conspiradores. No creemos necesario entretenernos con más ejemplos.

Algunos aspectos merece la pena destacar por las derivaciones que conllevan; así, por ejemplo, las fronteras intergenéricas son tan lábiles y al paradigma genérico se superpone tan frecuentemente el carácter adjetivo de la modalidad que, además de reproducir el conflicto observable en otros códigos de la época, hacen más perceptibles los “chirridos" que resultan de llenar géneros 'viejos' (en el sentido canónico) con contenidos `nuevos'; por ello se comprende mejor que, si bien Lizardi repite esquemas tradicionales de la sátira, "su ironía y su crítica social adquirieran un sentido nuevo", según N. Salomón (1965; 169); que la suya no sea la "sátira fría y corrosiva de los enciclopedistas", como su humorismo tampoco tiene el tinte "sombrío de los románticos", al decir de A. Yáñez (1955: XV); que conjugue, pues, actitudes no fácilmente conciliables como los tonos (matizadamente) moralistas 
con el escepticismo y la cierta melancolía que rezuma todo humorismo de ley. Junto a las marcas genéricas que singularizan la naturaleza de los mecanismos formales desplegados, conviene tener en cuenta, asimismo, las marcas funcionales que conllevan tales mecanismos; en este sentido, debe colocarse en primera fila al periodista, natural y contextual, que Lizardi lleva dentro: la heterogeneidad de los receptores y su pretensión de llegar a todos se proyecta en los niveles del discurso con paralela heterogeneidad de temas, de formas genéricas, de estrategias técnicas y de lenguajes; si sus periódicos se enriquecen y literaturizan con recursos ficcionales, su novela emblemática, el Periquillo, tiene mucho de periódico, tanto en su diseño originario (publicación por entregas, complemento de grabados, listas de suscriptores, anticipaciones y cortes pragmáticos...), como en su textualidad («miscelánea divertida, crítica y moral» que integra una amplia gama de géneros breves). Añádase que el juego de los espacios ficcionales y de las voces interpuestas reflejan especularmente, desde ángulos diversos, la realidad inmediata, cuando no acaban refractando paródica, humorística, irónicamente, a través de la hibridación, de la palabra bivocal, de la ironía de la ficción..., las intenciones del segundo amo ${ }^{22}$. A la vista, en fin, de lo expuesto, parece claro que "la figura y la obra de Lizardi son más complejas, paradójicas y conflictivas de lo que se ha querido suponer", como bien ha advertido Jacobo Chencinski (1963: 74); y que, sin desdeñar en absoluto la incidencia de la vida y la historia en su obra, ésta se explica mayormente como un conjunto orgánicamente literario de relaciones intergenéricas orientadas en todo momento por el objetivo ilustrado de la utilidad pública.

\section{Bibliografía}

AÍNSA, F. (1984). "Tensión utópica e imaginario subversivo en Hispanoamérica". Anales de Literatura Hispanoamericana 13: 13-35.

ÁLVAREZ DE TEST, L. (1994). Ilustración, educación e independencia: las ideas de José Joaquín Fernández de Lizardi. México: UNAM.

ARIAS-CAMPOAMOR, J. F. (1952). Novelistas de México. Esquema de la historia de la novela mexicana (De Lizardi a 1950). Madrid: Cultura Hispánica.

22. Dice en este sentido Mijail M. Bajtín: "Más allá del relato del narrador leemos el segundo relato -el relato del autor que narra lo mismo que el narrador, pero refiriéndose además al narrador mismo-. Cada momento del relato lo percibimos claramente en dos planos: en el del narrador, en su horizonte semántico-objetual y expresivo, y en el plano del autor, que se expresa de manera refractiva en el mismo relato y a través de él. En ese horizonte del autor entra también, junto con todo lo narrado, el narrador mismo con su palabra" (1989: 131). 
AZUELA, M. (1976). "Cien años de novela mexicana” (1947) en Obras completas (3 vols.). México: FCE. III: 578-587.

BAJTIN, M. M. (1989). Teoría y estética de la novela. Madrid: Taurus.

CARTER, B. G. (1968). Historia de la literatura hispanoamericana a través de sus revistas. México: De Andrea.

CHENCINSKY, J. (1963). Estudio preliminar a José Joaquín Fernández de Lizardi. Obras, I. Poesías y fábulas. (Eds. J. Chencinsky y M. Schneider). México: UNAM.

—, (1968). Estudio preliminar a José Joaquín Fernández de Lizardi. Obras, III. Periódicos: El Pensador Mexicano. (Eds. Mª. R. Palazón y J. Chencinsky). México: UNAM.

CHIBÁN, A. y ALTUNA, E. (1989). "La transtextualidad del Siglo de Oro español en «El desierto prodigioso». Thesaurus XLIV (3): 567-579.

DÍAZ-MIGOYO, G. (1990). La diferencia novelesca. Lectura irónica de la ficción. Madrid: Visor.

ESTÉVEZ MOLINERO, Á. (1995). "Procedimientos retórico-éticos de la ficción en El Periquillo Sarniento". Glosa 6: 47-61.

FERNÁNDEZ DE LIZARDI, J. J. (1968). Obras. III. Periódicos: El Pensador Mexicano. (Eds. M ${ }^{\text {a }}$ R. Palazón y J. Chencinsky). México: UNAM.

-, (1970). Obras. IV. Periódicos: Alacena de Frioleras / Cajoncitos de la Alacena / Las sombras de Heráclito y Demócrito / El Conductor Eléctrico. (Ed. Mª. R. Palazón). México: UNAM.

-, (1975). Conversaciones del Payo y el Sacristán en Obras. V. Periódicos: El Amigo de la Paz y de la Patria / El Payaso de los Periódicos / El Hermano del Perico que cantaba la Victoria / Conversaciones del Payo y el Sacristán. (Ed. Ma . R. Palazón). México: UNAM.

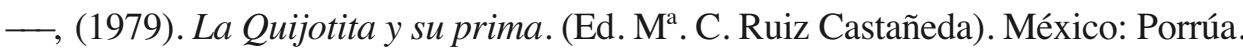
—, (1982a). Obras. VIII. El Periquillo Sarniento (t. I y II). Obras IX. El Periquillo Sarniento (t.III, IV y V) / Noches tristes y día alegre. (Ed. F. Reyes Palacios). México: UNAM.

—, (1982b). Folletos de Fernández de Lizardi. Reproducción facsímil de las primeras y únicas ediciones realizadas (1813-1827) en La obra de José Joaquín Fernández de Lizardi. Prosa periodística (vol. II). (Ed. R. Oviedo). Madrid: Universidad Complutense.

—, (1997). El Periquillo Sarniento. (Ed. C. Ruiz Barrionuevo). Madrid: Cátedra.

-, (2001). Don Catrín de la Fachenda. Noches tristes y día alegre. (Eds. R. Oviedo y A. Mejías). Madrid: Cátedra.

FRANCO, J. (1983). "La heterogeneidad peligrosa: Escritura y control social en vísperas de la independencia mexicana”. Hispamérica 34-35: 3-34. 
GOIC, C. (1992). "La novela hispanoamericana colonial" en Historia de la literatura hispanoamericana (3 vols.). (Coord. L. Í. Madrigal). Madrid: Cátedra. I: 369-406.

GONZÁLEZ OBREGÓN, L. (1938). Novelistas mexicanos. Don José Joaquín Fernández de Lizardi (El Pensador Mexicano). México: Botas.

GUTIÉRREZ, J. I. (1999). Manuel Gutiérrez Nájera y sus cuentos. De la crónica periodística al relato de ficción. New York: Peter Lang.

HAROLD, D. (1949). "José Joaquín Fernández de Lizardi” en Latin American Leaders. New York: Wilson.

HENRÍQUEZ UREÑA, P. (1947). Historia de la cultura en la América Hispánica. México: FCE.

—, (1978). "El descontento y la promesa" en La utopía de América. Caracas: Ayacucho.

HODUSEK, E. (1970). "Las novelas de Fernández de Lizardi”. Iberoamericana Pragensia IV: 23-39.

JOSET, J. (1982). "La utopía degradada de J. J. Fernández de Lizardi” en Memoria del XX Congreso del Instituto Internacional de Literatura Iberoamericana (Budapest, 1981). Budapest: Dpto. de Español de la Universidad Eötvös Loránd de Budapest.

LOTMAN, Y. M. (1982). Estructura del Texto Artístico. Madrid: Istmo.

MARTíNEZ, J. L. (1955). "José Joaquín Fernández de Lizardi y los orígenes de la novela en México" en La expresión nacional. Letras mexicanas del siglo XIX. México: Imprenta Universitaria.

MORAÑA, M. (1989). "El Periquillo Sarniento y la ciudad letrada”. Revista de Estudios Hispánicos 23: 113-26.

OCAMPO, A. (1967). Diccionario de escritores mexicanos. México: UNAM.

OVIEDO, R.(Ed.) (1982). Folletos de Fernández de Lizardi. Reproducción facsímil de las primeras y únicas ediciones realizadas (1813-1827) en La obra de José Joaquín Fernández de Lizardi. Prosa periodística (Vol. II). Madrid: Universidad Complutense.

PALACIOS SIERRA, M. (1965). Estudios preliminares e índices del periodismo de J. J. Fernández de Lizardi. México: UNAM.

PALAZÓN, Mª R. (1970). Presentación de José Joaquín Fernández de Lizardi. Obras. IV. Periódicos: Alacena de Frioleras / Cajoncitos de la Alacena / Las sombras de Heráclito y Demócrito / El Conductor Eléctrico. (Ed. $\mathrm{M}^{\mathrm{a}}$. R. Palazón). México: UNAM.

—, (1981). Presentación de José Joaquín Fernández de Lizardi. Obras, X. Folletos (1811-1820). (Ed. Mª . R. Palazón). México: UNAM. 
POLIC-BOBIC, M. (1995). "Lizardi y la ilustración: un coqueteo". Studia Romanica el Anglica Zagrabensia XL: 79-103.

RAMA, Á. (1984). La ciudad letrada. Hanover: Ediciones del Norte.

REYES, A. (1975). "El Periquillo Sarniento y la crítica mexicana" en Simpatías y diferencias. (Ed. A. Castro Leal). México: Porrúa.

REYES PALACIOS, F. (1982). Prólogo a El Periquillo Sarniento en J. J. Fernández de Lizardi. Obras. VIII. El Periquillo Sarniento (t.I y II). Obras IX. El Periquillo Sarniento (t. III, IV y V) / Noches tristes y día alegre. México: UNAM.

RUIZ BARRIONUEVO, C. (1991). "La cultura ilustrada de José Joaquín Fernández de Lizardi”. Suplementos del Anuario de Estudios Americanos XLVII (2): 75-94.

—, (1997). Introducción a J. J. Fernández de Lizardi. El Periquillo Sarniento. Madrid: Cátedra.

RUIZ CASTAÑEDA, Ma . C. (1974). El periodismo en México. 450 años de historia. México: Ed. Tradición.

SÁINZ DE MEDRANO, L. (1989). "Historia y utopía en Fernández de Lizardi" en La Historia en la Literatura Hispanoamericana. Hanover: Ediciones del Norte.

SALOMON, N. (1965). "La crítica del sistema colonial de la Nueva España en El Periquillo Sarniento". Cuadernos Americanos 138 (1): 167-179.

SEOANE, $M^{\mathrm{a}}$. C. (1977). Oratoria y periodismo en la España del siglo XIX. Valencia: Castalia; Fundación Juan March.

SPELL, J. R. (1926). "Fernández de Lizardi: The Mexican Feijoo". The Romanic Review XVII: 339-348.

- (1931). The Life and Works of José Joaquín Fernández de Lizardi. Filadelfia: University of Pennsylvania.

—, (1956). "The Intelectual Background of Lizardi as Reflected in El Periquillo Sarniento". Publications of the Modern Language Association LXXI (3): 414-432.

-, (1964). "Lizardi and Taxco". The Library Chronicle of the University of Texas VII (4): 3-25.

URBINA, L. G. (1965). La vida de México y la literatura mexicana durante la guerra de la Independencia. (Ed. A. Castro Leal). México: Porrúa.

VELASCO VALDÉS, M. (1955). Historia del periodismo mexicano. México: Porrúa.

WOLD, R. (1970). “Libros que se leían en México de 1808 a 1812” en El Diario de México, primer cotidiano de Nueva España. Madrid: Gredos.

YÁÑEZ, A. (1955). Estudio preliminar a José Joaquín Fernández de Lizardi, El Pensador Mexicano. México: UNAM. 